\title{
A PATIENT WITH SCHINZEL-GIEDION SYNDROME AND A REVIEW OF 20 PATIENTS
}

\author{
Nobuhiko OKamoto, ${ }^{1, *}$ Muneyuki Takeuchi, ${ }^{2}$ Hiroyuki Kitajima, ${ }^{3}$ \\ and Shozo HosoKaWA ${ }^{4}$ \\ ${ }^{1}$ Department of Planning and Research, ${ }^{2}$ Department of Anesthesiology, \\ ${ }^{3}$ Department of Neonatal Medicine, and ${ }^{4}$ Department of Urology, \\ Osaka Medical Center and Research Institute for Maternal and Child Health, \\ 840 Murodo-cho, Izumi 590-02, Japan
}

\begin{abstract}
Summary The Schinzel-Giedion syndrome is characterized by severe midface retraction, multiple skull anomalies, clubfeet, and cardian and renal malformations. So far, 20 patients have been reported. This is the first report of the syndrome demonstrated in Oriental patients. In surviving patients, severe growth and developmental deficiency is a common finding.

Key Words Schinzel-Giedion syndrome, congenital hydronephrosis, multiple congenital anomaly syndrome
\end{abstract}

\section{INTRODUCTION}

In 1978, Schinzel and Giedion (1978) described a new syndrome with severe midface retraction, multiple skull anomalies, clubfeet, and cardiac and renal malformations in sibs. So far 20 patients with the Schinzel-Giedion syndrome have been reported (Donnai and Harris, 1979; Kelley et al., 1982; Burck, 1982; Saal et al., 1989; Pul et al., 1990; Al-Gazali et al., 1990; Maclennan et al., 1991; Robin et al., 1993; Verloes et al., 1993; Herman et al., 1993; Labrune et al., 1994). We report a new patient with the Schinzel-Giedion syndrome and a review of the literature on the subject.

\section{CLINICAL REPORT}

The patient is a female newborn infant who was born at term as the second child to non-consanguinous healthy Japanese parents. Fetal ultrasonography revealed congenital hydronephrosis and oligohydroamnios. At term, her birth

Received January 31, 1995; Revised version accepted April 10, 1995.

* To whom correspondence should be addressed. 
weight was 2,638 $\mathrm{g}$, body length $45 \mathrm{~cm}$, and head circumference $32.5 \mathrm{~cm}$. Apgar scores were 7 and 7 at 1 and $5 \mathrm{~min}$, respectively. The hospital course was complicated by poor feeding, apneic attacks and cardiac failure. Echocadiography revealed dysplastic tricuspid valves, tricuspid insufficiency, ASD and VSD. Abdominal ultrasonography showed left hydronephrosis and hydroureter.

At age 6 months, examination showed coarse dysmorphic features which included a wide anterior fontanel and sutures, frontal bossing, midface retraction, depressed nasal bridge, short upturned bulbous nose, submucosal cleft palate, deep set eyes, characteristic deep grooves under the eyes, short neck (Fig. 1a), and hyperconvex nails. She had a narrow thorax, remarkable abdominal distension and bilateral talipes equinovarus (Fig. 1b).

Radiographic examinations revealed widely patent anterior fontanel and sutures, a sclerotic skull base, a steep base of the skull, broad ribs and a hypoplastic

(a)
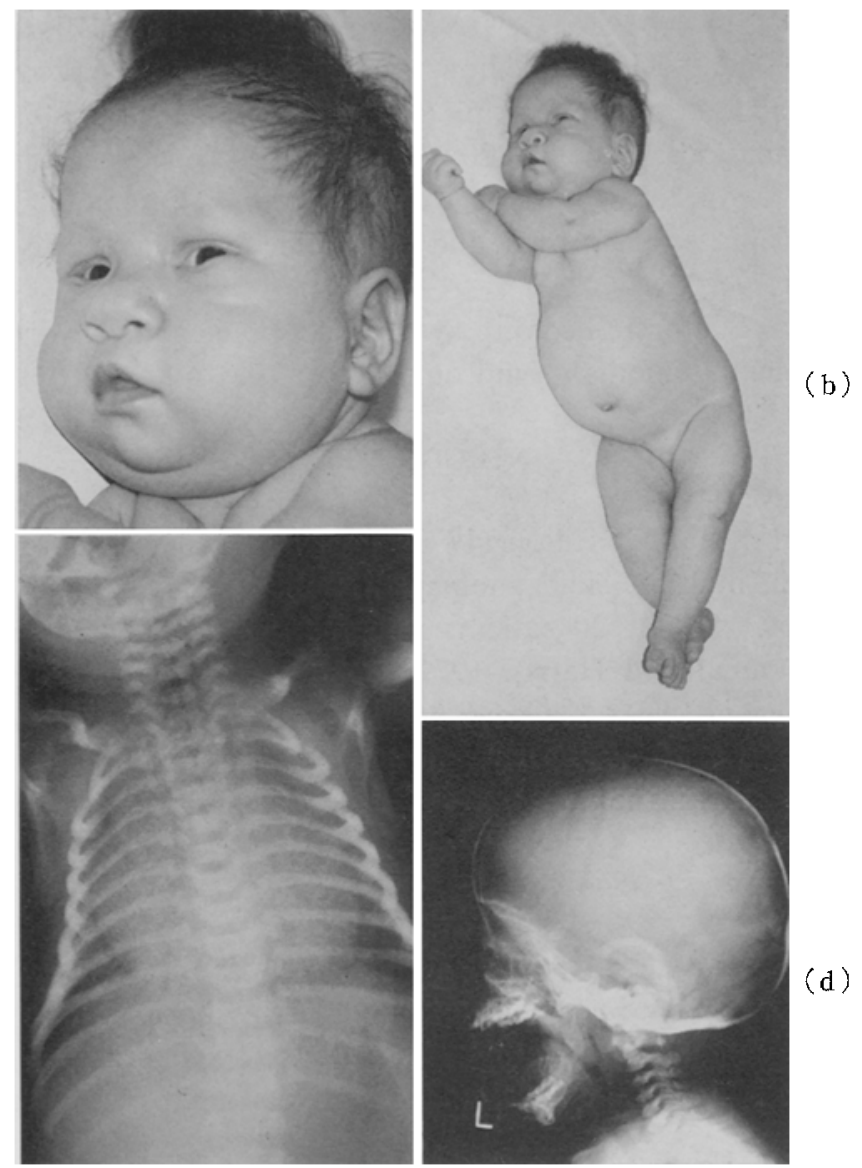

Fig. 1. a, Coarse dysmorphic features. b, Narrow thorax and distended abdomen. c, d, Chest and skull X-rays. 
thorax (Figs. 1c and d). The pubic bones were hypoplastic. Mild widening of the distal femora and hypoplastic distal phalanges were noted. Screening for metabolic abnormalities was negative. Her karyotype was $46, \mathrm{XX}$.

She was floppy and head control was established at the age of 8 months. Her foot joints were spastic and she could not sit alone or crawl at the age of 14 months. Her weight was $8,900 \mathrm{~g}(-0.4 \mathrm{SD})$, body length $70.7 \mathrm{~cm}(-2.1 \mathrm{SD})$, and head circumference $44 \mathrm{~cm}(-1 \mathrm{SD})$.

\section{DISCUSSION}

The Schinzel-Giedion syndrome is a newly described multiple congenital anomaly syndrome. Twenty patients have been reported (Table 1). This syndrome is characterized by dysmorphic facial appearance, urogenital anomalies, cardiac anomalies, and generalized skeletal dysplasia. Intrauterine growth is normal. Midfacial hypoplasia with a coarse appearance and deep grooves under the eyes are clues to diagnosis. Verloes et al. (1993) described the face as a figure '8' shape. They observed changing craniofacial abnormalities: hirsutism vanishes, midface retraction becomes less prominent, and bitemporal narrowing more obvious.

Some patients have anomalies in the central nervous system. Maclennan et al. (1991) described a case with increasing ventriculomegaly, intraventricular bands, and subependymal pseudocysts on neurosonography. Robin et al. (1993) found generalized atrophy, hypoplasia of the basal ganglia, atrophic corpus callosum, and hypoplastic pons on MRI.

Bilateral or unilateral hydronephrosis is an important clue to diagnosis. Prenatal detection may be possible. Some patients have stenosis of the ureteropelvic junction or vesicoureteral reflux. Genital anomalies in female patients include deep interlabial sulcus, hypoplasia of labia majora or minora, hymenal atresia and short perineum. In males, hypospadias, hypoplastic scrotum and short penis are often seen (Al-Gazali et al., 1990).

Radiographic studies of the skeleton are imperative in this syndrome. The skull base is steep and shows sclerotic change. Poorly mineralized cranium, wide occipital synchondrosis, widely patent anterior fontanelle, and wormian bones are found. Other features are broad ribs, hypoplastic pubic bones, thick long bones diaphyses, widening of distal femora, tibial bowing, hypoplasia of distal phalanges in hands and feet and short first metacarpals.

Complications of hepatoblastoma (Burck, 1982) and malignant sacrococcygeal teratoma (Robin et al., 1993) were reported. An increased incidence of embryonic tumors might be a component of the Schinzel-Giedion syndrome (Robin et al., 1993).

The basic defect of this syndrome is unknown. Autosomal recessive inheritance seems to be plausible. Further studies are necessary to elucidate the nature of this syndrome. 


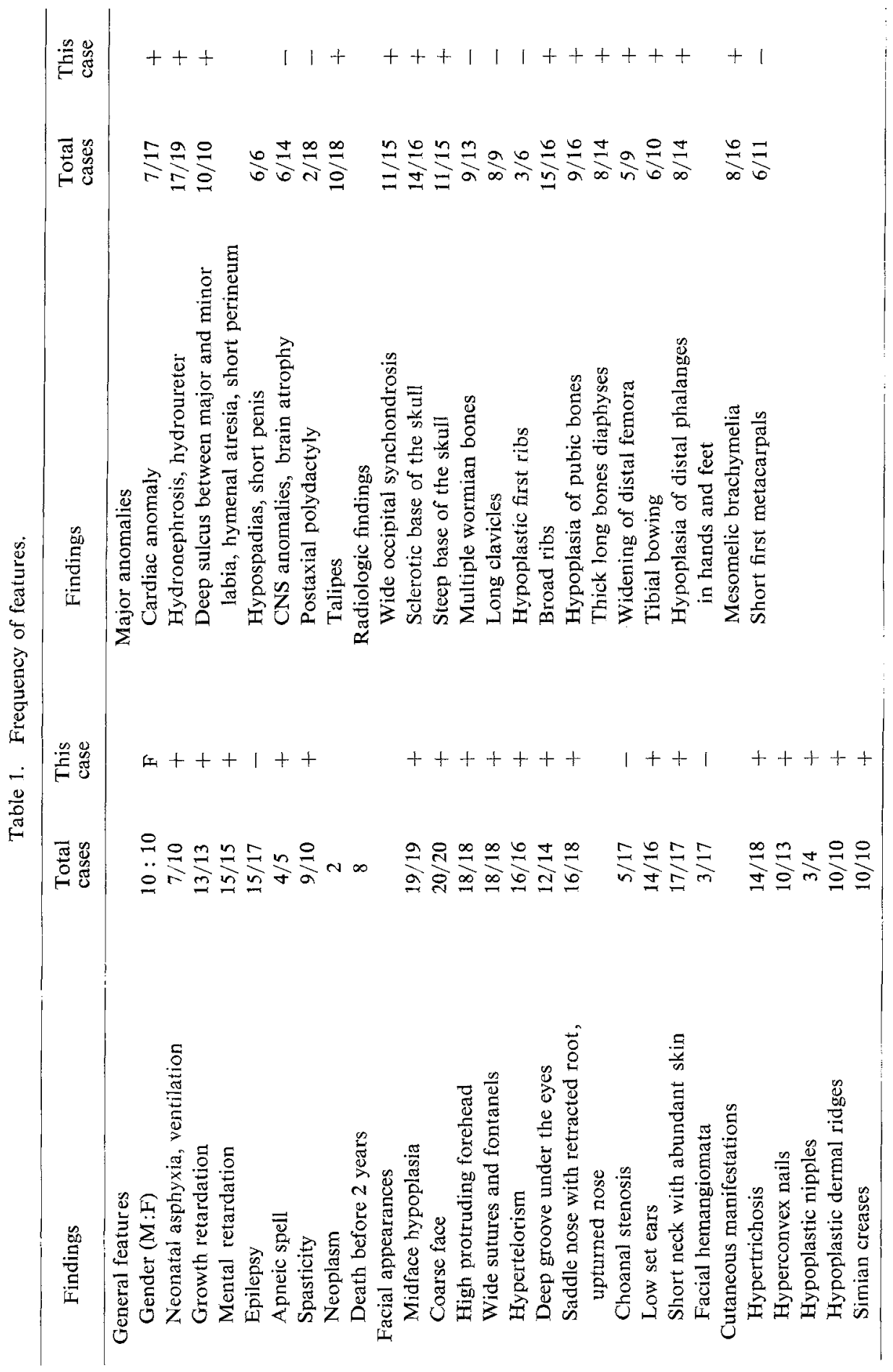




\section{REFERENCES}

Al-Gazali LI, Farndon P, Burn J, Flannery DB, Davison C, Mueller RF (1990): Schinzel-Giedion syndrome. J Med Genet 27: 42-47

Burck U (1982): Mittelgesichtshypoplasie, Skelettanomalien, Apnoen, Retardierung-eine weitere Beobachtung. In: Tolksdorf M, Spranger J (eds). Klinische Genetik in der Padiatrie. 3. Symposium in Kiel, Jargang 8, Heft 5.

Donnai D, Harris R (1979): A further case of a new syndrome including midface retraction, hypertrichosis, and skeletal anomalies. J Med Genet 16: 483-486

Herman TE, Sweetser DA, McAlister WH, Dowton SB (1993): Schinzel-Giedion syndrome and congenital megacalyces. Pediatr Radiol 23: 111-112

Kelley RI, Zackai EH, Charney EB (1982): Congenital hydronephrosis, skeletal dysplasia and severe developmental retardation: the Schinzel-Giedion syndrome. J Pediatr 100: 943-946

Labrune P, Lyonnet S, Zupan V, Imbert M-C, Goutieres F, Hubert P, Le Merrer M (1994): Three new cases of the Schinzel-Giedion syndrome and review on the literature. Am J Med Genet 50: $90-93$

Maclennan AC, Doyle D, Simpson RM (1991): Neurosonography and pathology in the SchinzelGiedion syndrome. J Med Genet 28: 547-549

Pul M, Yilmaz N, Komsuoglu B (1990): The Schinzel-Giedion syndrome. A case report and review of the literature. Clin Pediatr 29: 235-239

Robin NH, Grace K, DeSouza TG, McDonald-McGinn D, Zackai EH (1993): New finding of Schinzel-Giedion syndrome: a case with a malignant sacrococcygeal teratoma. Am J Med Genet 47: 852-856

Saal HM, Rosenbaum KN, Samango-Sprouse CA (1989): The Schinzel-Giedion syndrome: insight into phenotype and natural history (Abstract). Pediatr Res 25: 78A

Schinzel A, Giedion A (1978): A syndrome of severe midface retraction, multiple skull anomalies, clubfeet, and cardiac and renal malformations in sibs. Am J Med Genet 1: 361-375

Verloes A, Moes D, Palumbo L, Elmer C, Francois A, Bricteux G (1993): Schinzel-Giedion syndrome. Eur $J$ Pediatr 152: 421-423 